\title{
CHARACTERISTIC OF INDIVIDUAL INDICATORS OF ENDOGENOUS INTOXICATION IN THE EXPERIMENTAL ASTHMA DYNAMICS AND THEIR CORRECTION BY THIOTRIASOLIN
}

\author{
Marta Kolishetska \\ Department of Pathophisiology \\ Danylo Halytskiy Lviv National Medical University \\ 69 Pekarska str., Lviv, Ukraine, 76018 \\ marta.kolishetska@gmail.com
}

\begin{abstract}
Aim of this work was to find out the specifics of changes in endogenous intoxication, middle mass molecules (MMM) and erythrocyte intoxication index (EII) in the blood of animals for experimental asthma in different periods of its development and to correct them by thiotriazolin.

Material and methods. Researches were carried out on 72 guinea-pigs (males), which were divided into 6 groups for 12 animals in each of them. The last sixth group included animals that were treated by thiotriazolin. The drug thiotriazolin rate of $100 \mathrm{mg} / \mathrm{kg}$ intramuscularly since 23rd day of the experiment for 10 days was administered in the animals of sixth group.

Experimental model of bronchial asthma was restored on guinea-pigs by the V. I. Babych method (1979). In all groups of animals there were determined the middle mass molecules concentration in blood in the wave of $254 \mathrm{~nm}$ by I. A. Volchehorskiy, D. A. Dyatlova, E. I. Lvovska and others methods and EII by V. K. Kazymyrko V. I. Maltsev methods. Numerical results were adapted with static method using Student's criteria.

Results of research. The highest level of endogenous intoxication in the blood was in the fifth group of guinea pigs with asthma (33rd day), indicating the direct dependence of the antigenic effect on their severity. Using of the thiotriazolin within 10 days (from 23rd to 33rd day) caused the decrease of the MMM254 concentration and EII in serum compared with a group of guinea pigs, that were not entered the medicine. It approved its treating effect.

Conclusions. So, the research of middle mass molecules and erythrocyte intoxication index indicators in different periods of experimental asthma showed their gradual increase in serum of guinea pigs with the greatest severity in 33rd day of the experiment. It might indicate the development of endogenous intoxication animals. But the using of thiotriazolin caused the decreasing of these indicators. That gives a reason to state its positive effect on some markers of endogenous intoxication and feasibility of further researches.

Keywords: bronchial asthma, endogenous intoxication, middle mass molecules, erythrocyte intoxication index.
\end{abstract}

\section{Introduction}

Bronchial asthma (BA) is a chronic inflammatory disease of the respiratory tract, based on the increased reactivity of the bronchial tree of immunological and non-immunological genesis [1]. Chronic inflammation with bronchial hyperactivity is manifested with such symptoms as recurrent wheezing, breathlessness, stiffness in the chest, coughing, especially at night and early morning. These episodes are usually associated with widespread, but variable bronchial obstruction which reverse spontaneously or because of therapy [2, 3].

Over the last 20-30 years a significant increase of the asthma incidence is noticed in all countries (prevalence in children of Ukraine is $0,2-1 \%$ ). Moreover there is a harder course of disease, the emergence of hormone-dependent forms and adverse effects of the disease, early children and adolescents disability $[4,5]$. The research of the pathogenesis of asthma is still one of the most important issues in modern medicine. We know from the literature that various diseases are accompanied by the development of endogenous intoxication syndrome [6]. Endogenous toxins cause the clinical course and prognosis of the underlying disease. Endotoxemia appears in case of this pathology [6-8]. And it breaks the peripheral vascular tone, blood rheology, kinetic and mechanical properties of blood cells. Finally, it leads to hypoxia. Hypoxia causes hyperlipidemia, hyperglycemia, activation of free radical reactions cascade accumulation of inflammatory cytokines, prostaglandins $[9,10]$. A sharp hypoxia is one of important links of pathogenesis of syndrome of endogenous 
intoxication, which motion deepens depression of function of organs of detoxication and egestion. Toxins block the places of fastening of molecules of albumin that carries out a transport function for many medical preparations $[11,12]$. It, in its turn, results in the decline of efficiency of treatment. Under the conditions an organism needs pharmacological support for normalization of these violations that is why only standard treatment can be not enough [13-15]. It is possible to provide for in connection with the above-mentioned such application in the complex of curative measures of patients with asthma of the thiotriazolin, that has detoxic, antioxidant, membranostabilizing, immunomodulating, and antiischemic anti-inflammatory properties [16], improves processes of reparation, will allow to optimize the results of treatment, namely: to decrease the level of endogenous intoxication, reduce the terms of removal of clinical displays of illness, decrease time of stay sick in permanent establishment. In relation to application of thiotriazolin at the used for setting fire diseases of breathing organs, in particular to asthma, then the volume of scientific information on this question is insignificant. It grounds expediency of the detailed study of efficiency of thiotriazolin at the asthma.

\section{Aim}

Find out the specifics of changes in endogenous intoxication, middle mass molecules (MMM) and erythrocyte intoxication index (EII) in the blood of animals for experimental asthma in different periods of its development and to correct them by thiotriazolin.

\section{Material and methods}

All experiments on laboratory animals carried out with following the European Convention for the protection of vertebrate animals used for experimental and other scientific purposes (Strasbourg, 1986), Council Directive 2010/63/EU, the Law of Ukraine 3447-IV "protection animals from the cruelty," the general ethics of animal experimentation adopted by the first national Congress on bioethics in Ukraine (2001). The researches were carried out on 72 guinea-pigs (category: Cavia porcellus, males). The weight of each one was 180-220 g. They were divided into 6 groups for 12 animals in each of them. Among the first group (control) were intact guinea-pigs. Among the second group were animals with an experimental BA ( $5^{\text {th }}$ day). Among the third group were guinea-pigs on the $19^{\text {th }}$ day of the experiment. The fourth group consisted of animals with an experimental BA ( $26^{\text {th }}$ day) and the fifth group included guinea-pigs with an experimental BA ( $33^{\text {rd }}$ day, before thiotriazolin using). The last sixth group included animals that were treated by thiotriazolin. The thiotriazolin rate of $100 \mathrm{mg} / \mathrm{kg}$ intramuscularly since $23 \mathrm{rd}$ day of the experiment for 10 days was administered in animals of sixth group the drug. For the purpose of detailed analysis and interpretation of indicators of endogenous intoxication in different days of the experiment were separated two periods of experimental asthma: early and late. The early period included a group of animals with BA on the 5th and 19th days of the experiment. Late period included guinea pigs on 26th and 33rd day of asthma. The experimental asthma model reproduced in guinea pigs by the method V. I. Babich (1979).

Animals were sensitized by a normal horse serum $(0.1 \mathrm{ml}$ intraperitoneally). Next three days they were entered subcutaneously $0.1 \mathrm{ml}$ of normal horse serum (NKS) with a setting in an autoclave BCG (1 mg BCG $1.0 \mathrm{ml} \mathrm{NKS}$ ). The next 14 days the animals were exposed to inhalation (using a spray) NKS to $1.0 \mathrm{ml}$ of serum for each guinea pig daily for 30 minutes in a sealed chamber. After this period every 7 days, guinea pigs had these NKS inhalation. Then the animals were decapitated. In all groups of guinea pigs there were determined the MMM concentration in blood in the wave of $254 \mathrm{~nm}$ by I. A. Volchehorskiy, D. A. Dyatlova, E. I. Lvovska and others methods [17] and EII by V. K. Kazymyrko V. I. Maltsev methods [18]. Numerical results were adapted with static method using Student's criteria.

\section{Results of the research}

Dynamics of endogenous intoxication increasing in the blood of guinea pigs in experimental asthma are presented in Table $\mathbf{1 .}$ 
Table 1

The MMM and EII levels in the blood of guinea pigs in experimental asthma $(\mathrm{M} \pm \mathrm{m})$

\begin{tabular}{ccccc}
\hline Research form & $\begin{array}{c}\text { Term of } \\
\text { disease (days) }\end{array}$ & $\begin{array}{c}\text { Animal } \\
\text { number }\end{array}$ & $\begin{array}{c}\text { MMM254, } \\
\text { conditional units }\end{array}$ & EII, \% \\
\hline Intact animal. Control & 5 & 12 & $0,367 \pm 0,01$ & $30,4 \pm 1,6$ \\
& 19 & 12 & $0,487 \pm 0,004$ & $46,47 \pm 1,9$ \\
Guinea pigs in bronchial asthma & 26 & 12 & $0,506 \pm 0,005$ & $49,29 \pm 2,8$ \\
& 33 & 12 & $0,596 \pm 0,004$ & $56,53 \pm 2,4$ \\
& & 12 & $0,603 \pm 0,003$ & $58,26 \pm 2,7$
\end{tabular}

Using of the thiotriazolin within 10 days (from 23rd to 33rd day) caused to the decrease of the MMM254 concentration to $24,5 \%(r \leq 0,05)$ and EII $-28,9 \%(r \leq 0,05)$ in serum compared with a group of guinea pigs, that were not entered the medicine. (Fig. 1).

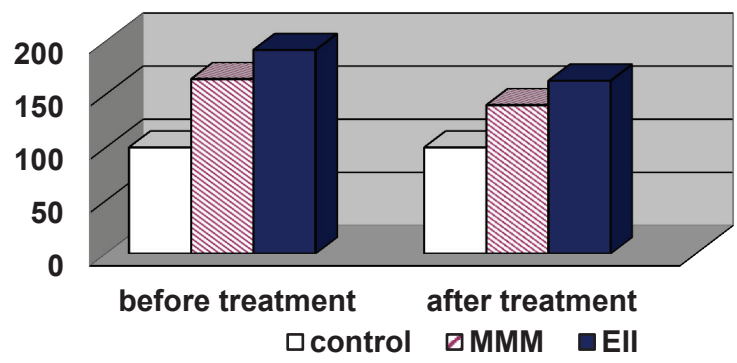

Fig. 1. The influence of thiotriazolin on the level of endogenous intoxication indexes in guinea pigs' blood in the asthma formation dynamics

\section{Discussion of results of the research}

The concentration of MMM in the blood of patients is a precise criterion of the presence and severity of endogenous intoxication among the other its indicators. At various pathological processes, especially in their long-term course in biological fluids is accumulated a significant amount of metabolic products, most of which is the so-called middle molecules, the substances average molecular weight (from 300-500 to 5,000 D). They have a negative affect on the metabolic processes in the body $[6,19]$. The concentration of MMM in the blood of patients is a quite precise criterion of the presence and severity of the "metabolic toxicity" [6, 20]. Middle molecules in small amounts are present in every healthy person. The main part of them consists of peptides, glycopeptides, degradation products of fibrinogen, albumin, thrombin, collagen fragments, other substances of protein nature and derived lipids, phospholipids, and others. This index is used as a marker of toxicity of various origins to determine the severity of the pathological process. As we can see from the data, the highest level of endogenous intoxication in the blood was in the fifth group of guinea pigs with asthma (33rd day), indicating the direct dependence of the antigenic effect on their severity. Thus, in the second and third group of animals in this experiment its level in the blood raises to $32,7 \%(\mathrm{r} \leq 0,05)$ and $37,9 \%(\mathrm{r} \leq 0,05)$ respectively in comparison with the control group. The same changes are seeing in the extent of the pathological process. Thus, in the late period of the experimental model MMM254 level further increases to $62,4 \%(r \leq 0,05)$ on the 26 th day and $64,3 \%(r \leq 0,05)$ on the 33 rd day of experimental asthma in comparison with the first group.

An erythrocytic index of intoxication is also one of the important markers of endogenous intoxication. The results showed a similar nature and one direction. Thus, during the experiment 
a growth rate was investigated in 52,9\% $(\mathrm{r} \leq 0,05)$ and $62,1 \%(\mathrm{r} \leq 0,05)$ early in the development of experimental asthma (5 and 19th day) in comparison with the control group of animals. Later on the 26th day of experimental models of the disease there is a further increase of EII in the blood by $86 \%(r \leq 0,05)$ opposite intact guinea pigs, and on the $33 \mathrm{rd}$ day growth rate reached $91,6 \%(\mathrm{r} \leq 0,05)$ in comparison with the first group.

The drug thiotriazolin rate of $100 \mathrm{mg} / \mathrm{kg}$ intramuscularly since $23 \mathrm{rd}$ day of the experiment for 10 days was administered in the animals of sixth group.

After using of the thiotriazolin rate of $100 \mathrm{mg} / \mathrm{kg}$ intramuscularly since $23 \mathrm{rd}$ day of the experiment for 10 days the animals of sixth group were fixed the decreasing concentration of both indicators in serum compared with a group of guinea pigs that were not entered the medicine. It approved its treating effect.

\section{Conclusions}

1. So, the research of middle mass molecules and erythrocyte intoxication index in the blood of animals in different periods of experimental asthma showed their gradual increasing in serum of guinea pigs with the greatest severity in 33rd day of the experiment. It might indicate the development of endogenous intoxication animals.

2. But the using of thiotriazolin caused the decrease of these indicators. That gives a reason to state its positive effect on some markers of endogenous intoxication and feasibility of further researches.

\section{References}

[1] Alifanova, S. V. (2013). Risk Factors Of Bronchial Asthma in Children. Actual questions in pharmaceutical and medical science, 3 (13), 4-7.

[2] Regeda, M. S., Furdychko, L. O., Kolishetska, M. A. (2012). Bronchial Asthma. Lviv, 147.

[3] Regeda, M. S., Pogoretska, Y. O. (2013). Bronchial Asthma:changes of separated indicators of endogenous intoxication and their correction by thiotriazoline. Actual problems of transport medicine, 3 (33), 111-115.

[4] Global strategy for asthma management and prevention. National institutes of health. National Heart, Lung and Blood Institute. Revised 2014. Available at: http://www.ginasthma.org

[5] Hedlin, G., Konradsen, J., Bush, A. (2012). An update on paediatric asthma. European Respiratory Review, 21 (125), 175-185. doi: 10.1183/09059180.00003212

[6] Shmoilov, D. K., Karimov, I. Z., Odynets, T. N. (2012). Pathogenic role of endogenous intoxication. Lab. Diagnostic, 2, 65-69.

[7] Kit, B. K., Simon, A. E., Ogden, C. L., Akinbami, L. J. (2011). Trends in Preventive Asthma Medication Use Among Children and Adolescents, 1988-2008. PEDIATRICS, 129 (1), 62-69. doi: 10.1542/ peds.2011-1513

[8] Waserman, S., Nair, P., Snider, D., Conway, M., Jayaram, L., McCleary, L. M. et. al. (2012). Local and systemic immunological parameters associated with remission of asthma symptoms in children. Allergy, Asthma \& Clinical Immunology, 8 (1), 16. doi: 10.1186/1710-1492-8-16

[9] Pike, K. C., Crozier, S. R., Lucas, J. S. A., Inskip, H. M., Robinson, S. et. al. (2010). Patterns of fetal and infant growth are related to atopy and wheezing disorders at age 3 years. Thorax, 65 (12), 1099-1106. doi: $10.1136 /$ thx.2010.134742

[10] Uddin, M., Nong, G., Ward, J., Seumois, G., Prince, L. R., Wilson, S. J. et. al. (2010). Prosurvival activity for airway neutrophils in severe asthma. Thorax, 65 (8), 684-689. doi: 10.1136/thx.2009.120741

[11] Cornwell, W., Kim, V., Song, C., Rogers, T. (2010). Pathogenesis of Inflammation and Repair in Advanced COPD. Seminars in Respiratory and Critical Care Medicine, 31 (03), 257-266. doi: 10.1055/ s-0030-1254066

[12] Gernez, Y., Tirouvanziam, R., Chanez, P. (2010). Neutrophils in chronic inflammatory airway diseases: can we target them and how? European Respiratory Journal, 35 (3), 467-469. doi: 10.1183/09031936.00186109

[13] Agache, I., Akdis, C., Jutel, M., Virchow, J. C. (2012). Untangling asthma phenotypes and endotypes. Allergy, 67 (7), 835-846. doi: 10.1111/j.1398-9995.2012.02832.x 
[14] Umanec, T. R. (2011). Clinic-anamnestic features of fenotypes of bronchial asthma for children. Perinatology and paediatrics, 2 (46), 69-71.

[15] Hesselmar, B., Enelund, A.-C., Eriksson, B., Padyukov, L., Hanson, L. A., Aberg, N. (2012). The Heterogeneity of Asthma Phenotypes in Children and Young Adults. Journal of Allergy, 2012, 1-6. doi: $10.1155 / 2012 / 163089$

[16] Opanasenko, G. V., Potter, O. O., Phrancuzova, S. B., Mankovska, I. N. (2012). Influence of the thiotriasoline on the state of pro- and antioxidant balance in soft fabrics of paradont at the terms of chronic stress. Tavricheskiy medico-biological vistnyk, 15 (3), 246-249.

[17] Volchegorskiy, I. A., Diatlov, D. A., Lvovskaya, E. I. et. al. (1997). Middle molecules" as probable regulators of erythrone system in skiers. Lab. Diagnostic, 1, 11-16.

[18] Kazymyrko, V. K., Maltsev, V. I. (2007). Antioxidant system and its function in a human body. Ukrainian Health, 5, 15-24.

[19] Antypkin, Y. G. et. al. (2010). The clinical discipling from diagnostics and treatment of bronchial asthma in children. Health of Ukraine, 3 (14), 39-41.

[20] Bezrukov, L. O., Bezrukov, O. K., Ivanov, L. A. et. al. (2011). The chosen questions of diagnostics and treatment of bronchial asthma in children. Chernivtsi: City, 203. 